\title{
DYNAMICS OF USE AND SUPPLY: An Analytic Lens for Information Systems Research
}

\author{
Jennifer Whyte \\ Imperial College London
}

\begin{abstract}
This paper describes a dual focus on the dynamics of use and supply as an analytic lens for deconstructing and examining the IT artifact. It then gives an example of the use of this approach in empirical work. Over the last 20 years, most research has focused either on organizational use of information systems or on their development and supply. There is a need to bring these two pictures into combined focus to examine creation, definition, and modification of emergent systems. Building on work in the innovation studies tradition, an analytic lens is developed to examine the evolving IT artifact across the boundaries of use and supply. Its application is demonstrated in a study of virtual reality in the construction sector. Sensemaking in the software organizations that supply virtual reality applications to the sector and in the engineering, design, and construction organizations that use them is explored. The comparison exposed a mismatch of priorities, which poses a challenge to the establishment and continued validity of these applications. The paper concludes by reflecting on how this approach builds on, and may help us extend, existing theoretical understandings of information systems and how research that uses the approach may inform practice.
\end{abstract}

Keywords: Analytic lens, IT artifact, use, supply, virtual reality

\section{INTRODUCTION}

"IS is characterized by the problems we study rather than the theories we use," argues Paul (2002, p. 175). Others agree. There is current concern over the lack of interest in, or sophistication of analysis of, technologies within information systems in use (Cornfield 2003; Orlikowski and Iacono 2001). Within the North American research community this has led to renewed calls to focus information systems research on the IT 
artifact and its immediate antecedents and consequences (Benbasat and Zmud 2003). Yet this artifact has remained impervious to our attempts to scrutinize it.

When I reread papers from the 1984 IFIP conference (Mumford et al. 1985), I am amazed at the absence in the 1980s oftechnological context as a motivator for theorizing or as an actor in the debate about research method. Yet it is hard to deny the extent to which information systems and the structures of their supply and use have changed since that conference. There has been a decline in the use of the mainframe and a diffusion of personal computers, Windows operating systems and related word processing, spreadsheet, and Internet applications (Campbell-Kelly 2001; Mowery 1996). The personal computer application software industry has grown and matured to serve the needs of organizational users (Campbell-Kelly 2001) and there has been a shift away from application development as a local (in-house) team activity toward organizations purchasing expertise, consultancy, software, and services through the market (Cornfield 2003). Our theoretical understandings of information systems have remained largely blind to such changing technological, historical, and industrial contexts.

This theoretical blindness may be in part due to the focus of much empirical research and theorizing over the last 20 years. The majority of work in the IS literature has focused exclusively on organizational use of information technologies and information systems. From this body of work, we begin to develop a rich picture of the role of the information system in the modern enterprise. We benefit from theoretical developments such as structuration theory (Brooks 1997; DeSanctis and Poole 1994; Orlikowski 1992), and from detailed empirical studies that test and extend our theoretical understandings, often through a focus on a particular application (e.g. on computer aided design: Brooks 1997; Sohal 1997; Yetton et al. 1994). However, in my opinion, this work is stunted by a "black-box" view of the technology itself and an assumption that it is possible to disregard structures of supply. These are fair boundaries and assumptions when technology is mature, but huge failings when we are studying emergent technologies that are created, defined, and modified at the same time as being implemented and used.

A quite separate picture of information systems emerges through the academic work on the development and supply of information technologies and information systems. Sociologists of technology, such as Latour (1987) and Callon (1987) have directed our attention to the role of the research laboratory and the political and contested nature of technologies in the making. Their approaches have gained supporters within the IS community and have been applied to information systems (e.g., Bloomfield 1995; Monteiro and Hanseth 1996). Scholars within the innovation studies tradition have also typically concentrated on supply, but they (and their supporters within the IS community) direct attention to the evolving structure and dynamics of computer hardware and software industries (Hung 2003; Mowery and Langlois 1996; Steinmueller 1995) or conduct critical studies of individual software firms and their strategies (Lee 2000). While the sociologists of science and innovation studies scholars (and their respective supporters) have markedly different epistemological positions, what they share here is a concern with the dynamic processes through which technologies come into being.

Hence we have two separate approaches to information systems, with studies of use focusing on how new information technologies come to be used and studies of supply 
focusing on how new information technologies come to be (Orlikowski and Iacono 2001). Information systems researchers have not brought these separate pictures into combined focus to examine the way IT artifacts are created, defined, and modified in use over time. Yet, features of relevance to our core interest in the IT artifact lie across the interface between use and supply. As long as our research community focuses exclusively on use or exclusively on supply, then the true nature of the evolving IT artifact will slip through our grasp.

In this paper I describe a dual focus on the dynamics of use and supply as an analytic lens for deconstructing and examining the IT artifact. My interest is in emerging technology that is still technology in the making but is beginning to be tentatively implemented, played with, and used within organizations. I illustrate the methodological approach that I outline through empirical work conducted as an inquiry into emerging virtual reality (VR) use in the construction sector. I then draw conclusions and outline directions for future work.

\section{BRINGING THE EVOLVING IT ARTIFACT INTO FOCUS}

There is growing recognition that a sense of technology as infinitely malleable has led to a failure to recognize the specificities of particular applications and the constraints they might impose (Mutch 2002). Recent work has sought to shift the attention of the IS research community back to the IT artifact itself. This paper follows in this tradition, taking as its starting point the conceptualization given by Benbasat and Zmud (2003), who show the IT artifact at the core, surrounded by the task(s), then structure(s), and then context(s), as shown in Figure 1. I try to articulate components of the IT artifact, rather than treating it as a black-box. I discuss how a focus on the dynamics of use and supply could provide a means of keeping the nature of the IT artifact in focus in empirical work.

Although the conceptualization of Benbasat and Zmud is used as a spur to further theorizing, it is problematic. One issue is that it captures only a snapshot in time, presenting a static interpretation of the IT artifact and associated task(s), structure(s), and context(s). Another is that the definition has, I contend, an unsatisfactorily recursive nature. Benbasat and Zmud conceptualize the IT artifact as

the application of IT to enable or support some task(s) embedded within a structure(s) that itself is embedded within a context(s). Here, the hardware/ oftware design of the IT artifact encapsulates the structures, routines, norms and values implicit in the rich contexts within which the artifact is embedded (2003, p. 186).

By attempting to evade a narrow technology focus, I feel that Benbasat and Zmud overburden the idea of the IT artifact to the extent that technological aspects simply slip from view. The aim here is to develop and extend this line of theorizing, addressing some of the weaknesses. In the following subsection, I articulate different components of a modern information system; I then discuss the dynamics of use and supply as an analytic lens for information systems research. 


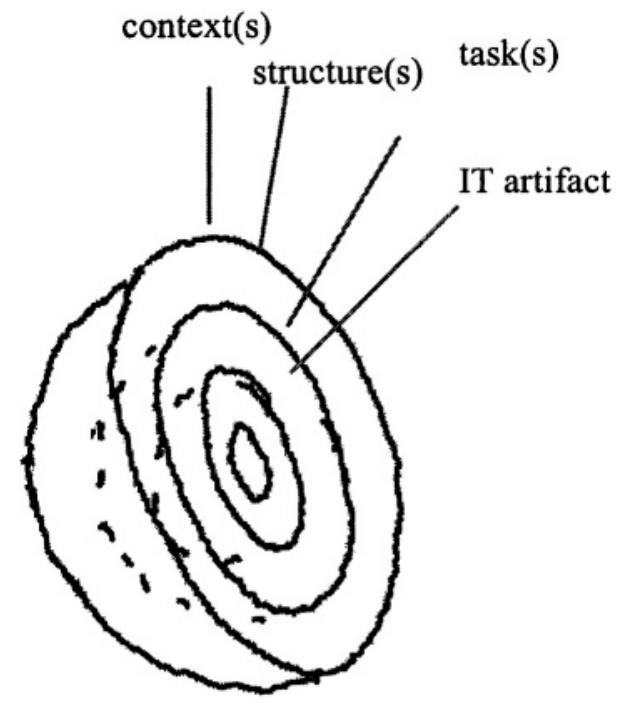

Figure 1. Context(s); Structure(s), Tasks(s) and the IT Artifact in Use, Described as Concentric Rings by Benbasat and Zmud (2003)

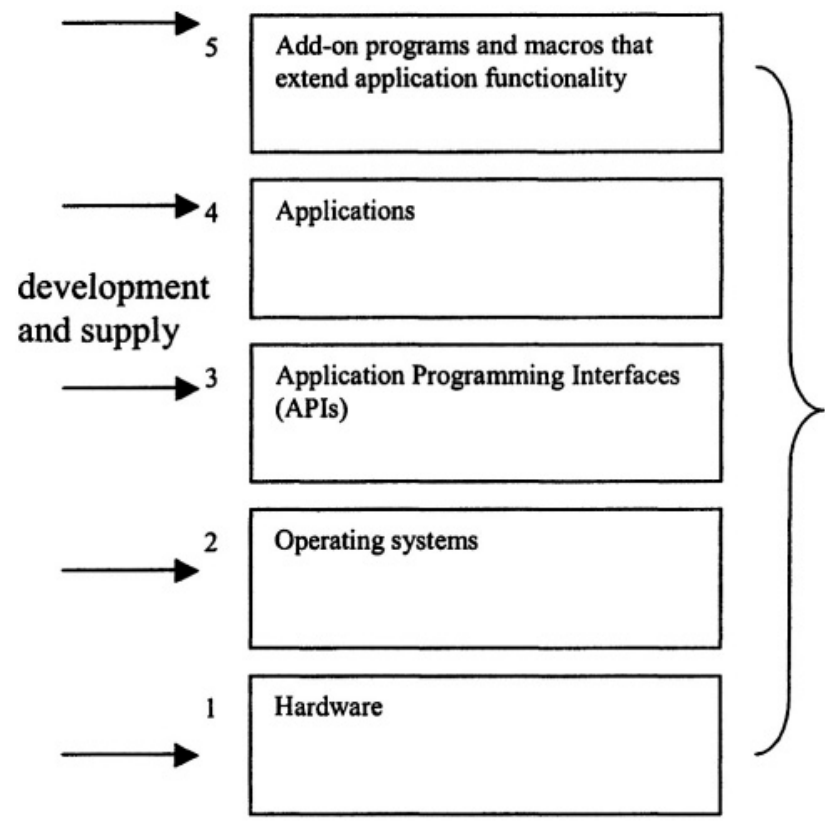

Figure 2. Articulation of Different Technological Levels Within Complex Information Systems 


\subsection{Articulating the Structure of the IT Artifact}

Information systems are complex products. Many firms are involved in the production of systems and subsystems. Figure 2 describes a five level model of the generic (contemporary) information system as composed of (1) hardware; (2) operating system; (3) application programming interfaces; (4) applications; and (5) add-on programs, plug-ins, and macros that extend functionality. Such a model is historically and culturally situated. It not untypical of basic computing texts, but it is useful to IS researchers as it has a number of implications.

First, it allows us to be clearer about our technological unit of analysis. Much IS research is actually mainly concerned with subsets of the overall information system, such as, for example, work that focuses at level 4 on the organizational use of applications (e.g., studies of CAD implementation given earlier), with only marginal interest in the use of their add-on programs, plug-ins, and macros; or the underlying application programming interfaces, operating systems, or hardware.

Second it allows us to explain how developments at the different technological levels may be occurring at different speeds, and are driven by different sets of users and suppliers. Suppliers of a particular solution at the application level, for example, may treat the available application programming interfaces as a given. They may be surprised when competing application programming interfaces emerge that serve the needs of other application suppliers.

\subsection{Dynamics of Use and Supply}

Researchers in the innovation studies field have looked at the introduction of new technologies from a systemic perspective. I build on a tradition of work in this field which looks at both production and use (Lundvall 1992, 2003) to suggest that a focus on the dynamics of use and supply may be helpful as an analytic lens for IS research. Here supply is looked at from the perspective of use and use is looked at from the perspective of supply. To return for a moment to Benbasat and Zmud's suggestive diagram, this could be seen to be expanded as shown in Figure 3.

My concern here is to focus on the evolving IT artifact through a comparison and contrast of the contexts of use and supply. Like Caelli et al. (2003), I use the term analytic lens to refer to the methodological and interpretive presuppositions that a researcher brings to bear on his or her data. In describing a dual focus on the dynamics of use and supply as an analytic lens, I am using dualism as an analytic device to compare and contrast characteristics and explore interrelationships between use and supply. In the next section I provide an example of empirical work in which this approach has been used.

\section{VIRTUAL REALITY IN CONSTRUCTION}

This section describes the use of a dual focus on use and supply to interpret a study of VR in the construction sector. The study was conducted using an embedded multiple case study method, coupled with historical study of the development and status of VR technologies. 


\section{Looking at supply from $\longrightarrow$ the perspective of use \\ Looking at use from the perspective of supply}

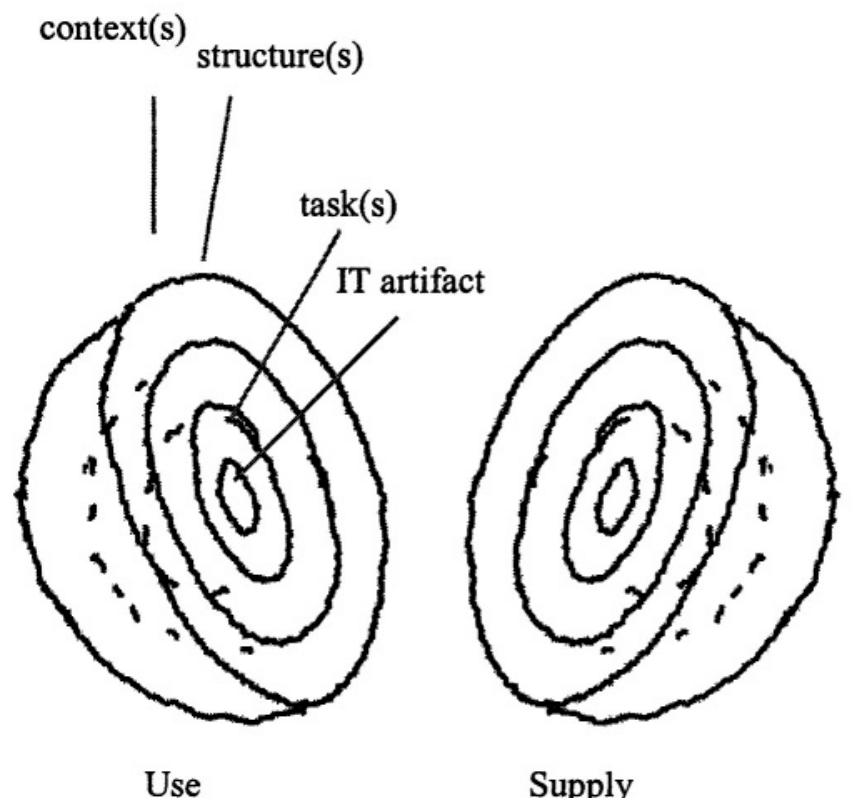

Figure 3, Context(s), Structure(s), Tasks(s), and the IT Artifact in Both Use and Supply

I was motivated to undertake this work as, in the academic literature of the late 1990s, VR was being portrayed as an important new technology awaiting a dominant design (Swann and Watts 2000; Watts et al. 1998). A government initiative was aimed at promoting its use within UK industry (DTI 2000) and this highlighted construction as a key sector for use. However, I felt that there was a thin evidential basis for such conclusions and policies. In my research I wanted to collect data on, analyze, and assess the success or failure of organizational uses of VR applications within engineering, design, and construction firms and also the potential of VR suppliers to address their needs.

The construction sector is highly fragmented with a large number of firms involved in the design, production, and maintenance of the built environment. Characteristics of the construction process which affect the nature of innovation include its project-based nature (Gann and Salter 2000), the unusual extent to which it is regulated (Pries and Janszen 1995), and the collaborative and competitive relationships between different players in supplier networks-manufacturers, designers, specialists, contractors, 
subcontractors, developers, users, professional industry associations, and regulatorswithin which changes occur (Gann 2000).

The technological context was explored through participation in the activities of the VR and visualization community in the UK and internationally (from 1997 through 2003) and desk-based research to study the historical development of graphics technologies, including the array of technologies that underlie CAD and VR applications. Case-study research was conducted in 11 user organizations and 6 suppliers in 2000-01.

Further details of the industrial context, data-collection methods, and validation have been reported elsewhere (Whyte 2003), where there is also a fuller description of findings. The focus here is on the analysis and interpretation of the findings using dynamics of use and supply as an analytic lens for decomposing and studying the IT artifact. In the following sections I describe the technological context, and then summarize the salient features of use and supply before comparing, contrasting, and exploring the role of interrelationships between use and supply in establishing legitimacy of an emerging technology.

\subsection{Emergent Uses in the Construction Sector}

The user organizations studied ranged from an architectural practice with low use of VR at the customer interface, to a major real estate owner that had developed a realtime interactive 3D application for viewing construction scheduling and CAD data, to a consultant engineering and project management practice that had established visualization groups in both the United States and the United Kingdom. The organizations with the largest investment in virtual reality were consultant engineers, contractors, and real estate owners. These organizations use virtual reality for systems integration, simulating dynamic operation, and coordination of detail design within the project team and supply chain. They are concerned with reducing risk, increasing technological innovation and improving business processes. Some, like the consultant engineering and project management practice mentioned above, employed specialist modelers to create and maintain virtual reality models over the life of a project, particularly on large and complex building and infrastructure projects such as railways, airports, shopping malls, and theme parks.

A wider group of organizations use virtual reality for interactions with end-users, clients, managers, funding institutions, and planners. The models used for these tasks may be quite different in nature from those used by construction professionals. Here VR was being used to offer the customer a greater understanding of the design and a limited design choice from a palate of options.

All of the user organizations using VR within construction-related production processes were found to have a pattern of requirements that included the ability to transfer data to VR packages from $\mathrm{CAD}$ packages, in which the majority of their design work took place. Virtual reality is also being used by architects to develop new markets outside the construction sector. This brings architects (reconceived as cyberspace architects or architects of the physical and virtual realm) into competition with Web designers, human-computer interaction experts, and programmers. 


\begin{tabular}{|c|c|c|c|}
\hline 5 & $\begin{array}{r}\text { Add-on programs and macros } \\
\text { that extend application } \\
\text { functionality }\end{array}$ & $\begin{array}{l}\text { Plug-in visualization } \\
\text { modules in CAD, GIS, } \\
\text { and engineering } \\
\text { analysis tools }\end{array}$ & \\
\hline 4 & Applications-VR packages & $\begin{array}{l}\text { New applications by } \\
\text { specialist suppliers }\end{array}$ & $\begin{array}{l}\text { VR applications } \\
\text { by established } \\
\text { suppliers }\end{array}$ \\
\hline 3 & $\begin{array}{c}\text { Application Programming } \\
\text { Interfaces (APIs)- } \\
\text { 3D Graphic Engines }\end{array}$ & $\begin{array}{c}<- \text { VRML, Open GL, } \\
\text { Open 3D }\end{array}$ & $\begin{array}{l}\text { pen Inventor -> } \\
\text { Iris Performer }\end{array}$ \\
\hline \multirow[t]{2}{*}{2} & Operating systems & Windows & UNIX \\
\hline & Hardware & Personal Computers & $\begin{array}{l}\text { Workstations } \\
\text { and bespoke } \\
\text { hardware } \\
\text { solutions }\end{array}$ \\
\hline
\end{tabular}

Figure 4. Different Technological Components in VR Systems

\subsection{Dynamics and Structure of Supply}

The companies studied included three types of suppliers: (1) established VR suppliers, (2) specialist VR suppliers that have knowledge of construction practices, and (3) resellers and model builders. In this section I will concentrate on the first two types.

Both the users and suppliers struggled to make sense of competing technologies at different technological levels and Figure 4 illustrates this. The established suppliers are shown as providers of applications for UNIX-based workstations and bespoke hardware, which up until the late 1990s was the sole focus of their activity. At this time, developments in the PC market led a number of specialist suppliers to recognize the market opportunity and to deliver interactive real-time 3D applications for specific construction process; and also led established VR suppliers to make software available on the PC platform. The established VR suppliers have then subsequently developed collaborations with leading CAD, graphics information systems (GIS), and analysis packages to deliver their solutions as visualization plug-ins to standard packages.

One of the case studies was of a major VR supplier that had about 15years experience developing modeling and visualization software. Up until four years previously, everything this company had produced had been designed to run on SGI hardware as that was the only thing that served the needs of the visual simulation community.

Now today we can take the same techniques that we do on the high end and deliver them on common PC hardware which is directly attributable to all of the wonderful advances in processing speed but more importantly graphic 
card architecture and that is being driven...by kids! The gaming industry, I mean it's wonderful!

For the generic supplier, the construction users were a small minority group, particularly in terms of their buying capacity. They had a set of demanding requirements that did not lie comfortably within the strategic direction of these supplier companies. The suppliers were looking to diversify as the market for applications on bespoke hardware was now in decline even for the demanding real-time 3D applications that these suppliers delivered. They perceived a need to port their existing applications to new hardware platforms and operating solutions and to widen their customer base.

The specialist suppliers studied, while using broadly the same set of technologies, do not use the term virtual reality in their own marketing literature, preferring terms such as $4 \mathrm{D}-\mathrm{CAD}$ and interactive design review. Generic suppliers and the specialist new entrants also had a very different understanding of the relationship between CAD and VR. The company described above had a background in military training applications, particularly flight simulation, and found the engineering, design, and construction firms' need for data exchange with $\mathrm{CAD}$ particularly problematic. The interviewee described their experience of the practices of construction users,

When they turn on the computer they are turning on their CADprogram... and CAD programs and virtual reality sometimes don't mix well, at least from our perspective they don't because we are into real-time visualization and that's a whole very focused discipline in $3 D$ visualization.

In contrast, a specialist supplier argued, "We are not replacing the CAD engineers. We need all that source data."

\subsection{Interrelationships between Use and Supply}

It is only through an analysis of both use and supply that a mismatch in priorities becomes apparent between construction sector users, for whom data exchange with CAD is of critical importance, and the generic VR supply industry, for which such data exchange is peripheral to use. This mismatch of priorities poses a challenge to the establishment and continued validity of these applications within construction. The construction sector is seen as a difficult sector by generic VR suppliers, and with a more recent increase in United States funding for military urban simulation applications, they may have become even less relevant to these suppliers, even in their urban simulation divisions.

The analysis has implications for the central concerns of WG 8.2 in research on organizational uses of information systems. For example Orlikowski (2000) describes users' interaction with a technology as recursive, arguing that in recurrent practice, users shape the technology structures that shape their use. This work presents a challenge to such a view, arguing that it shows only part of the picture. The ability of user organizations to influence adaptation of technologies is constrained by the priorities of other users at the level of the multi-technology product and at the level of underlying technologies. 
Virtual reality applications were not easily established within the construction sector. The vision of the future held by policy makers and academics in the late 1990s did not come to pass. There are questions to be asked about why it didn't, and about the future of interactive real-time 3D applications in construction. Generic VR suppliers and resellers conceived of virtual reality as an entirely separate application creating a sense of presence, but as we have seen for construction industry users, the access to engineering data and connectivity of CAD and VR was a major issues. One possible future would be for the technologies underlying VR to be used in plug-ins to major CAD packages. Indeed I see evidence that CAD packages are both developing advanced 3D graphics capabilities themselves and partnering with suppliers of VR software. These findings raise questions about how policy can or whether it should try to help foster particular visions of the future.

\section{CONCLUSIONS}

This paper is part of a shift in the attention of the IS research community back to the IT artifact itself. It argues that organizational use of technology is shaped and constrained by structures and dynamics that exist across the boundaries of use and supply. The analytic lens proposed examines interrelationships at this interface as a means of deconstructing and examining the evolving IT artifact as it begins to be implemented and used. I argue that this allows us to better understand the IT artifact at a range of different technological levels.

This has implications for the type of research methods used in empirical work. Using this approach, it is important that the researcher explores both structures of dynamics of use and supply. However, information systems are complex, and there are multiple boundaries between users and producers. Suppliers of multi-technology applications act as users of application programming interfaces as well as suppliers of applications to a range of industrial sectors and processes (where their users may have conflicting requirements). End-user organizations struggle to make sense of the different but often overlapping configurations of underlying technologies supplied to them in multi-technology packages. When engaged in such research, it is important to be clear about the unit of analysis and to this end I articulate different parts of the information system. In the study of virtual reality in the construction sector, I look primarily at the users and producers of virtual reality applications, but am able to articulate the impact of technological change at a range of different levels.

The analytic approach proposed would benefit from further theoretical and empirical work. It builds on work in the innovation studies tradition that has looked at complex product systems, and there would be merit in comparing and contrasting emerging patterns of development of information systems with historical patterns observed for other technological systems.

\section{REFERENCES}

Benbasat, I., and Zmud, R. W. "The Identity Crisis Within the IS Discipline: Defining and Communicating the Discipline's Core Properties," MIS Quarterly (27:2), 2003, pp. 183-194. 
Bloomfield, B. "Power, Machines and Social Relations: Delegating to Information Technology in the National Health Service," Organization (2:3/4), 1995, pp. 489-518.

Brooks, L. "Structuration Theory and New Technology: Analyzing Organizationally Situated Computer-Aided Design," Information Systems Journal (7), 1997, pp. 133-151.

Caelli, K.; Ray, L.; and Mill, J. “'Clear as Mud': Toward Greater Clarity in Generic Qualitative Research," International Journal of Qualitative Methods (2:2), 2003.

Callon, M. "Society in the Making: The Study of Technology as a Tool for Sociological Analysis," in T. P. Pinch (Ed.), The Social Construction of Technological Systems, Cambridge, MA: The MIT Press, 1987, pp. 85-103.

Campbell-Kelly, M. "Not Only Microsoft: The Maturing of the Personal Computer Software Industry, 1982-1995," Business History Review (75), 2001, pp. 103-145.

Cornfield, K. G. "Information Systems and New Technologies: Taking Shape in Use," Working Paper Series 122, Department of Information Systems, London School of Economics and Political Science, 2003.

DeSanctis, G., and Poole, M. S. "Capturing the Complexity in Advanced Technology Use: Adaptive Structuration Theory," Organization Science (5:2), 1994, pp. 121-147.

DTI. UK Business Potential for Virtual Reality, London: Department of Trade and Industry, 2000.

Gann, D. Building Innovation: Complex Constructs in a Changing World, London: Thomas Telford, 2000.

Gann, D. M., and Salter, A. J. "Innovation in Project-Based, Service-Enhanced Firms: The Construction ofComplex Products and Systems," Research Policy (29:7/8), 2000, pp. 955-972.

Hung, S.-C. "The Taiwanese System of Innovation in the Information Industry," International Journal of Technology Management (26:7), 2003, pp. 788-800.

Latour, B. Science in Action: How to Follow Scientists andEngineers Through Society, Boston: Harvard University Press, 1987.

Lee, S. Y. T. "Bundling Strategy in Base-Supplemental Goods Markets: The Case ofMicrosoft," European Journal of Information Systems (9:4), 2000, pp. 217-225.

Lundvall, B.-Å.. (Ed.). National Systems of Innovation, London: Pinter, 1992.

Lundvall, B.-Å. Product Innovation, Markets and Hierarchies, Copenhagen: DRUID, 2003.

Monteiro, L., and Hanseth, O. "Social Shaping of Information Infrastructure: On Being Specific About the Technology," in W. J. Orlikowski, G. Walsham, M. R. Jones, and J. I. DeGross (Eds.), Information Technology and Changes in Organizational Work, London: Chapman \&Hall, 1996, pp. 325-348.

Mowery, D. C. (Ed.). The International Computer Software Industry: A Comparative Study of Industry Evolution and Structure, Oxford: Oxford University Press, 1996.

Mowery, D. C., and Langlois, R. N. "Spinning Off and Spinning On: The Federal Government Role in the Development of the US Computer Software Industry," Research Policy (25:6), 1996, pp. 947-966.

Mumford, E.; Hirschheim,R.; Fitzgerald, G.; and Wood-Harper, A. T. (Eds.). Research Methods in Information Systems. Amsterdam: North-Holland, 1985.

Mutch, A. "Actors and Networks or Agents and Structures: Towards a Realist View of Information Systems," Organization (9:3), 2002, pp. 477-496.

Orlikowski, W. J. "The Duality of Technology: Rethinking the Concept of Technology in Organizations," Organization Science (3:3), 1992, pp. 398-427.

Orlikowski, W. J. "Using Technology and Constituting Structures," Organization Science (11:4), 2000, pp. 404-428.

Orlikowski, W. J., and Iacono, C. S. "Desperately Seeking the 'IT' in IT Research-A Call to Theorizing the IT Artifact," Information Systems Research (12:2), 2001, pp. 121-134.

Paul, R. J. "(IS) ${ }^{3}$ : Is Information Systems an Intellectual Subject?," European Journal of Information Systems (11:2), 2002, pp. 174-177. 
Pries, F., and Janszen, F. "Innovation in the Construction Industry, the Dominant Role of the Environment,“ Construction Management and Economics (13:1), 1995, pp. 43-51.

Sohal, A. "A Longitudinal Study of Planning and Implementation of Advanced Manufacturing Technologies," International Journal of Computer Integrated Manufacturing (10:1), 1997, pp. 281-295.

Steinmueller, W. E. "The U.S. Software Industry: An Analysis and Interpretive History," in D. C. Mowery (Ed.), The International Computer Software Industry, Oxford: Oxford University Press, 1995.

Swann, G. M. P., and Watts, T. P. "Visualization Needs Vision: The Pre-Paradigmatic Character of Virtual Reality," in S. Woolgar (Ed.), Virtual Society? Technology, Cyberbole, Reality, Oxford: Oxford University Press, 2000.

Watts, T.; Swann, G. M. P.; and Pandit, N. R. "Virtual Reality and Innovation Potential," Business Strategy Review (9:3), 1998, pp. 45-54.

Whyte, J. K. "Innovation and Users: Virtual Reality in the Construction Sector," Construction Management and Economics Special Issue on Innovation in Construction (21:6),2003,pp. 565-572.

Yetton, P. W.; Johnston, K. D.; and Craig., J. F. "Computer-Aided Architects: A Case Study of IT and Strategic Change," Sloan Management Review (35:4), 1994, pp. 57-67.

\section{ABOUT THE AUTHOR}

Jennifer Whyte is a research fellow at the Tanaka Business School, Imperial College London. She works within the Innovation Studies Centre and has particular interest in the development ofdigital tools and technologies for design and their uses within organizations. Her research is conducted in collaboration with leading firms in the UK and USA. She has published widely in journals and a book, with ongoing work looking at virtual prototyping in engineering practice. Jennifer can be reached at j.whyte@imperial.ac.uk. 